\title{
The pharmacological management of obesity
}

\author{
André Marais \\ Department of Pharmacology, School of Medicine, Faculty of Health Sciences, University of Pretoria, South Africa \\ Corresponding author,email:dramarais@gmail.com / andre.marais@up.ac.za
}

\begin{abstract}
Obesity is a growing phenomenon and a global concern. It is well-known that it plays a significant role in the development of several preventable diseases. The physiological mechanisms in regulating energy intake and expenditure are complex and remain a target area for current and future research. The absence of a golden standard in determining the body's composition provides for various measurement techniques, each with its own advantages and disadvantages. Lifestyle changes and reduced caloric intake form the backbone of any pharmacological intervention. A myriad of therapeutic agents are available which offer the provision for individualised treatment.
\end{abstract}

Keywords: anti-obesity agents, appetite, body composition, obesity, weight loss

\section{Introduction}

The World Health Organization (WHO) defines obesity and overweight as the accumulation of excessive and abnormal body fat in such a way that it has the potential to impair the health of an individual. ${ }^{1}$ The global prevalence of overweight and obesity has dramatically increased since 1980, when the average proportion of adults with a BMI of $25 \mathrm{~kg} / \mathrm{m}^{2}$ was estimated at $28 \%{ }^{2}$ The latest WHO statistics indicate that approximately $39 \%$ (1.9 billion) of adults above the age of 18 years are overweight and 13\% (600 million) are classified as obese. ${ }^{1}$ Supporting the trend in increase, it has been estimated that by the year 2025 , this figure will have risen to three billion people being overweight, and nearly 700 million being obese. The incidence of obesity in children is also on the increase, with an estimated 42 million children worldwide being affected. Many studies have shown the increase in risk for obese and overweight individuals to develop diabetes mellitus ${ }^{3}$, cardiovascular disease ${ }^{4}$, cancer $^{5}$, musculoskeletal disorders ${ }^{6}$, endocrine disorders ${ }^{7}$ and psychiatric disorders. ${ }^{8}$ Obesity is responsible for 3.4 million global deaths annually and accounts for $4 \%$ of years of life lost. It can therefore be classified as a pandemic. ${ }^{2}$

According to the most recent data on obesity published by the Social Progress Imperative (SPI), South Africa is ranked as the seventh "fattest" ( $\%$ of population with a BMI $\geq 30 \mathrm{~kg} / \mathrm{m}^{2}$ ) country in the world, while Bangladesh has the lowest global incidence of obesity. ${ }^{9}$ The SPI is an international organisation consisting of businesses, governments and civil society representing 133 countries reporting on global progress and success concerning various social and environmental challenges. Similar studies have shown South Africa to be very close to the global average, with a population overweight rate (BMI $25-30 \mathrm{~kg} / \mathrm{m}^{2}$ ) of $38.3 \%$ (Figure 1). ${ }^{10}$

\section{Determining the body fat composition}

There are several methods of determining the body's composition. The most accurate determination, and still the "theoretical golden standard", has its foundation on Archimedes' principle dating back to 250BC: "The buoyant force which water exerts on an immersed object is equal to the weight of water that the object displaces."11 Body fat can therefore be calculated by completely submerging a person in water and measuring the weight (volume) of displacement. Fat free mass has a density of $1.1 \mathrm{~kg}$ per litre (consisting of $72 \%$ water, $21 \%$ protein and $7 \%$ minerals), where fat has an average density of $0.9 \mathrm{~kg}$ per litre. Ignoring the presence of air and contents in the gastrointestinal tract, it can then be calculated that if a person weighs $100 \mathrm{~kg}$, he will displace 95 litres of water if he has a fat percentage of $50 \%$.

This is obviously impractical to perform in the clinical setup, thus a lack of an acceptable golden standard has led to various methods attempting to measure and calculate body fat. Each method has limitations, and therefore practitioners need to have adequate knowledge of these measuring techniques in order to make an accurate assessment.

\section{Bioelectrical Impedance Analysis (BIA)}

The use of electrical impedance entails the resistance to the flow of an electric current through the different body tissues. An algorithm is used to calculate total body water and fat free body mass, which is subtracted from the total body mass to give an estimation of body fat. ${ }^{12}$ BIA devices are commercially available and frequently used due to the low cost, portability and noninvasiveness of this procedure. Several factors may affect 


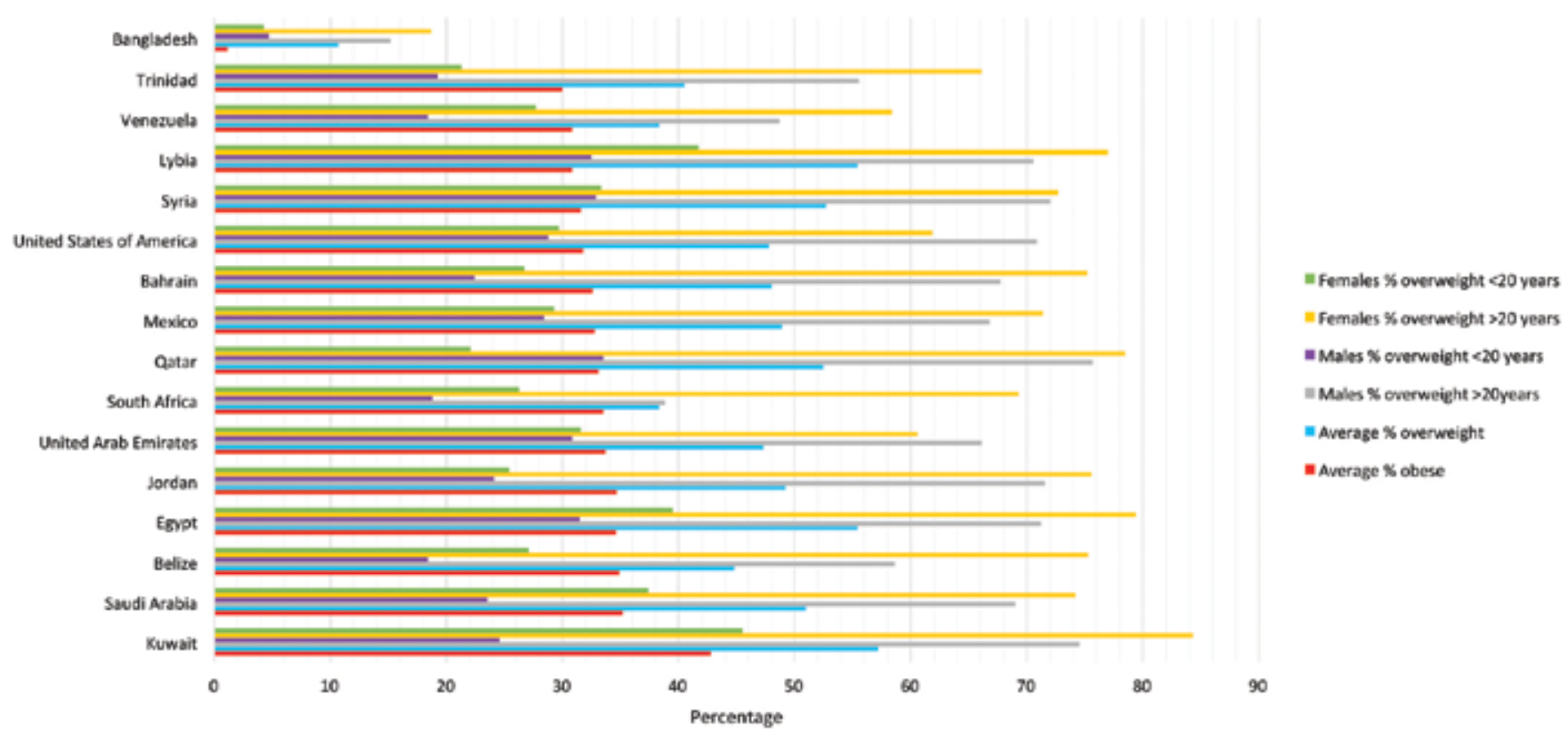

Figure 1. Top 15 "obese countries"

the accuracy of the reading, such as hydration status, exercise, ambient temperature, position of electrode placement and equipment calibration. The over- and underestimation of body fat by using BIA ranges between $7-14 \% .^{13}$

\section{Dual-energy X-ray Absorptiometry (DEXA)}

The use of DEXA has recently been advocated as a possible golden standard in determining body composition. Here an energy source produces photons at different energy levels, which are measured and used to differentiate between non-identical elemental profiles such as fat, bone and muscle. Body fat can accurately be calculated but the high costs involved make it an unlikely tool to be used in everyday practice. The instruments also have a maximum capacity of approximately $180 \mathrm{~kg}$, thus morbidly obese patients would not enjoy any benefit. ${ }^{14}$

\section{Anthropometric measurements}

Measuring triceps skinfold thickness (TSF) and mid-arm circumference (MAC) are noninvasive, inexpensive and easy to perform. From these two measurements the mid-arm muscle circumference (MAMC) can be calculated: [MAMC = MAC (3.1416 x TSF)]. The determined value is then compared to standardised age and gender reference ranges. A value below the fifth percentile demonstrates underweight, whereas values above the $90^{\text {th }}$ percentile imply obesity..$^{15}$ Anthropometric measurement arithmetic is more useful in monitoring long-term nutritional therapy in malnourished children than assessing obesity in adults. Using this method may under- or overestimate body composition by up to $10 \%$ in severely obese individuals. ${ }^{16}$

\section{Body Mass Index (BMI)}

$\mathrm{BMI}$ is calculated by dividing the weight by the height squared $\left(\mathrm{kg} / \mathrm{m}^{2}\right)$. It is easy to perform and is the most widely used clinical tool in the indirect assessment of obesity. A typical BMI, representing a normal weight range, is between $18.5 \mathrm{~kg} / \mathrm{m}^{2}$ and
$24.9 \mathrm{~kg} / \mathrm{m}^{2}$. Values less than 18.5 are considered underweight, whereas a value above 30 is classified as obese. Overweight represents values between 25 and 29.9. ${ }^{1}$ Although the definition and classification of obesity by the WHO make use of the BMI scale, it has serious limitations. Omitted variables such as age (body fat physiologically increases with age), sex (females inevitably have a higher body fat composition), fat distribution, muscle mass and bone structure (athletes or bodybuilders with high muscle mass and lower body fat), may result in an individual being misclassified due to either overestimation or underestimation of body fat. ${ }^{4,17}$ Some studies suggest that if the calculated BMI has to be compared to BIA, the overestimation of obesity could be as high as $30-60 \% .^{18}$

\section{Waist circumference (WC)}

Determining the waist circumference is another tool for classifying obesity with regards to the cardiovascular risk profile. Waist circumference measurement is useful in patients who are categorised as normal or overweight on the BMI scale $\left(\leq 30 \mathrm{~kg} / \mathrm{m}^{2}\right.$ ). Men are classified as "high risk" if the measured circumference at the midpoint between the lower margin of the last palpable rib and the top of the iliac crest exceeds $102 \mathrm{~cm}$. For women the threshold should not exceed $88 \mathrm{~cm}$. Measuring circumference at the level of the umbilicus may underestimate the true waist circumference. ${ }^{19}$ Measuring the WC only alludes to the location of fat, but not the absolute percentage of body fat. Using this method has an error rate of approximately $3 \%$, making it a more suitable evaluation tool compared to measuring the waist-to-hip ratio, $\mathrm{BMI}$ or BIA. 18,20

\section{Pharmacological therapy}

Pharmacological therapy is indicated for obese persons (BMI $\geq 30 \mathrm{~kg} / \mathrm{m}^{2}$ ), or overweight individuals with a BMI $\geq 27 \mathrm{~kg} / \mathrm{m}^{2}$ with associated complicating risk factors such as diabetes mellitus, hypertension, dyslipidaemia, sleep apnea and symptomatic 
osteoarthritis. ${ }^{21}$ Potentially serious side-effects limit its use to the short-term, although chronic therapy is indicated in resistant cases and where the benefit outweighs the risk. To date, no clinical trials on any anti-obesity drugs have been conducted for longer than four years. Patients should be extensively counselled prior to initiating drug treatment and unrealistic expectations explained. During the first month weight loss should exceed $2 \mathrm{~kg}$ and thereafter $5 \%$ within the next 3-6 months. Pharmacotherapy is considered to be effective if a patient achieves a weight loss of $10-15 \%$ in combination with lifestyle modifications in a period of 1-2 years. ${ }^{22}$ In order to maintain the achieved weight loss, patients should furthermore reduce their energy intake by at least $8 \mathrm{kcal} / \mathrm{kg}(34 \mathrm{~kJ} / \mathrm{kg}){ }^{23}$

For a substance to be regarded as an anti-obesity drug, it has to demonstrate a reduction of at least $5 \%$ in the baseline body weight. Agents used to treat obesity include appetite suppressants (sympathomimetic drugs), pancreatic lipase inhibitors, antidiabetic drugs, serotonin agonists, antiepileptic drugs, atypical antidepressants, hormones, combination preparations and various herbal and complementary medicines. The choice of agent should be individualised and governed by patient comorbidities, relative contraindications, available clinical trial evidence and clinical expertise. In addition to pharmacological therapy, all anti-obesity drugs should be prescribed with the premise of dietary caloric restriction and exercise. Table I below indicates some of the available and pending preparations in South Africa.

\section{Appetite suppressants}

All of the appetite suppressants are $\beta$-phenylamine derivatives which are structurally related to noradrenaline, dopamine and amphetamine. They increase the synaptic concentrations of noradrenaline and dopamine by 1) displacing these transmitters from their storage vesicles (amphetamine), 2) stimulating the release and inhibiting reuptake into presynaptic vesicles (phentermine, diethylpropion, phendimetrazine, d-norpseudoephedrine and sibutramine) and 3) directly agonising adrenergic receptors (phenylpropanolamine). Appetite is resultantly suppressed by the stimulation of the hypothalamic satiety centre in the brain. ${ }^{24}$ Sympathomimetic drugs therefore reduce food intake by causing early satiety. All of these drugs have a rapid onset of action and relatively short half-lives. They have been associated with numerous systemic side-effects including hypertension, palpitations, insomnia, cardiovascular toxicity and valve disease, stroke, depression and a high potential for abuse. This has led to them being highly scheduled substances, with some being discontinued worldwide (sibutramine and phenylpropanolamine). ${ }^{25}$ It is generally accepted that these agents should not be used for a period exceeding 12 weeks. Calculating or predicting a doseresponse relationship is difficult and the original degree of obesity has a considerable effect on the rate of absolute weight loss. Clinical data sheet reviews for the trial periods of 12 weeks have shown the following average weight loss per substance: phendimetrazine $140 \mathrm{mg}(3.6 \mathrm{~kg})^{26}$, phentermine $30 \mathrm{mg}$ $(8.1 \mathrm{~kg})^{27}$, diethylpropion $75 \mathrm{mg}(7.2 \mathrm{~kg})^{28}$

\section{Pancreatic lipase inhibitors}

The enzyme, pancreatic lipase, is present in the lumen of the stomach and small intestine. It is responsible for breaking down triglycerides into monoglycerides and absorbable free fatty acids. ${ }^{29}$ When lipase activity is blocked, triglycerides are excreted undigested, thereby reducing fat absorption from the diet and a reduction in caloric intake. Achieved weight loss with orlistat is dose dependent. A maximum dose of $120 \mathrm{mg}$ three times per day reduces intestinal fat absorption by almost $30 \%$, after which a ceiling effect is reached. ${ }^{30}$ The ordinary expected weight loss in 12 weeks is $4 \%$ of the initial body weight, but could increase to $>10 \%$ if treatment is continued beyond six months. ${ }^{31}$ Orlistat is a preferred option for obese patients with diabetes, dyslipidaemia and hypertension considering its efficacy and favourable safety profile. Adverse gastrointestinal side-effects are frequent, whereby $15-30 \%$ of patients will experience gastro-oesophageal reflux disease, flatus, faecal incontinence, frequent bowel movements or steatorrhoea. ${ }^{32}$ Drug interactions with orlistat are uncommon, except with cyclosporine, but it may inhibit the absorption of fat soluble vitamins A, D, E and K.

\section{Antidiabetic drugs}

Antidiabetic drugs commonly used to achieve weight loss include metformin (a biguanide) and liraglutide (a long-acting GLP1 agonist). Although the precise mechanism of these agents in weight reduction is not fully understood, several hypotheses have been proposed.

\section{Metformin}

Neuropeptide $Y$ (NPY) is a neurotransmitter present in the sympatho-adrenomedullary nervous system. The NPY pathway is stimulated by exercise, fasting, and energy loss which results in a suppression of sympathetic activity and an increased appetite..$^{33}$ Recent studies suggest that unlike its antidiabetogenic effects, metformin's anorectic properties are unrelated to its peripheral suppression of hepatic gluconeogenesis, increased insulin sensitivity or enhanced peripheral glucose uptake, but that a central mechanism is responsible. Metformin, like leptin, inhibits neuropeptide $\mathrm{Y}$ expression, thereby reducing food intake and decreasing body weight. ${ }^{34}$ Metformin is not primarily indicated as a weight loss drug, seeing that it does not achieve the required reduction of $5 \%$ or more loss in baseline weight. It is nonetheless useful in overweight individuals with elevated insulin levels at risk for type 2 diabetes. A customary weight loss of approximately $3 \mathrm{~kg}$ in eight weeks can be expected on a dose of $1000 \mathrm{mg}$ per day. ${ }^{35}$ If adherence to treatment is continued, metformin can sustain weight loss for at least 10 years. Sideeffects are uncommon and mainly include gastrointestinal upset (4\%) which usually resolves spontaneously. Patients with renal or hepatic insufficiency are at risk for developing lactic acidosis and it is therefore contraindicated in these individuals.

\section{Liraglutide}

Glucagon-like peptide 1 (GLP-1) is an incretin hormone which is secreted by the ileal $L$ cells in the presence of nutrients in the lumen of the small intestines. It stimulates the release of insulin from the pancreatic beta cells and inhibits glucagon release from the alpha cells, thereby causing a decrease in blood glucose 
Table I. Available agents in the management of obesity

\begin{tabular}{|c|c|c|c|c|c|}
\hline & $\begin{array}{l}\text { Drug } \\
\text { Schedule }\end{array}$ & Active ingredient & Dosage & $\begin{array}{l}\text { Maximum duration } \\
\text { of therapy }\end{array}$ & SEP*/quantity \\
\hline \multicolumn{6}{|l|}{ Appetite suppressants } \\
\hline Duromine ${ }^{\circ}$ - iNova & 5 & $\begin{array}{l}\text { Phentermine } 15 \mathrm{mg} \\
\text { Phentermine } 30 \mathrm{mg}\end{array}$ & Once daily & 3 months & $\begin{array}{l}\mathrm{R} 215.75(30) \\
\mathrm{R} 278.41(30)\end{array}$ \\
\hline Obesan $X^{\circ}$ - Technikon & 6 & Phendimetrazine $30 \mathrm{mg}$ & 1-2 twice daily & 6 weeks & R110.52 (30) \\
\hline Relislim ${ }^{\circ}$ - Loock Pharm & 6 & d-norpseudoephedrine $20 \mathrm{mg}$ & Max 60 mg per day & 4 weeks & R49.13 (30) \\
\hline Tenuate Dospan - Al Pharm & 6 & Diethylpropion 75 mg & Once daily & 4 weeks & R333.77 (30) \\
\hline \multicolumn{6}{|l|}{ Pancreatic lipase inhibitors } \\
\hline Xenecal $^{\circ}$ - Roche & 3 & Orlistat 120 mg & Three times daily & 12 weeks & $\mathrm{R} 876.00(84)$ \\
\hline \multicolumn{6}{|l|}{ Serotonin agonists } \\
\hline \multicolumn{6}{|l|}{ Antidiabetic drugs } \\
\hline Glucophage $^{\circ}-$ Merck $^{+}$ & 3 & $\begin{array}{l}\text { Metformin } 500 \mathrm{mg} \\
\text { Metformin } 850 \mathrm{mg} \\
\text { Metformin } 1000 \mathrm{mg} \\
\text { Metformin XR } 500 \mathrm{mg} \\
\text { Metformin XR } 1000 \mathrm{mg}\end{array}$ & $\begin{array}{l}\text { Max dose per day = } \\
2550 \mathrm{mg}\end{array}$ & $\mathrm{N} / \mathrm{A}$ & $\begin{array}{l}\text { R44.05 (90) } \\
\text { R64.32 (60) } \\
\text { R69.85 (60) } \\
\text { R68.86 (90) } \\
\text { R92.40 (40) }\end{array}$ \\
\hline Victoza ${ }^{\circ}$ - Novo Nordisk ${ }^{+}$ & 4 & Liraglutide 6 mg/ml & Max 1.8 mg daily & 12 months & R617 (3 ml pen) \\
\hline \multicolumn{6}{|l|}{ Antiepileptic drugs } \\
\hline Topamax - Janssen Pharm ${ }^{+}$ & 3 & $\begin{array}{l}\text { Topiramate } 25 \mathrm{mg} \\
\text { Topiramate } 50 \mathrm{mg} \\
\text { Topiramate } 100 \mathrm{mg} \\
\text { Topiramate } 200 \mathrm{mg}\end{array}$ & Max 400 mg daily & $\mathrm{N} / \mathrm{A}$ & $\begin{array}{l}\text { R380.25 (60) } \\
\text { R598.18 (60) } \\
\text { R1008.40 (60) } \\
\text { R1534.29 (60) }\end{array}$ \\
\hline \multicolumn{6}{|l|}{ Atypical antidepressants } \\
\hline \multicolumn{6}{|l|}{ Hormones } \\
\hline Eltroxin ${ }^{\circ}-$ Aspen $^{+}$ & 3 & $\begin{array}{l}\text { Levothyroxin } 0.05 \mathrm{mg} \\
\text { Levothyroxin } 0.1 \mathrm{mg}\end{array}$ & $\mathrm{N} / \mathrm{A}$ & $\mathrm{N} / \mathrm{A}$ & $\begin{array}{l}\text { R96.16 (100) } \\
\text { R121.72 (100) }\end{array}$ \\
\hline Ovitrelle ${ }^{\circ}-$ Merc $^{+}$ & 4 & a-Choriogonadotropin $6500 \mathrm{iU}$ & 125 iU daily & 6 weeks & $\begin{array}{l}\mathrm{R} 371.91(0.5 \mathrm{ml} \\
\text { prefilled syringe })\end{array}$ \\
\hline \multicolumn{6}{|l|}{ Combination preparations } \\
\hline Qsymia** & $\mathrm{N} / \mathrm{A}$ & $\begin{array}{l}\text { Topiramate } 46 \mathrm{mg} \text { or } 92 \mathrm{mg} \\
\text { Phentermine } 7.5 \mathrm{mg} \text { or } 15 \mathrm{mg}\end{array}$ & $\begin{array}{l}\text { Max } 92 \mathrm{mg} / 15 \mathrm{mg} \\
\text { once daily }\end{array}$ & 2 years & $\mathrm{N} / \mathrm{A}$ \\
\hline Contrave $^{* *}$ & $\mathrm{~N} / \mathrm{A}$ & $\begin{array}{l}\text { Naltrexone } 8 \mathrm{mg} \\
\text { Bupropion } 90 \mathrm{mg}\end{array}$ & Max 32 mg/360 mg & 24 weeks & $\mathrm{N} / \mathrm{A}$ \\
\hline
\end{tabular}

SEP: single exit price, $X R$ and $X L$ : extended-release tablets

" Single exit price, as listed in the Monthly Index of Medical Specialities. 2016;56(1)

"Not available in South Africa

+ Not registered for weight loss

levels. In addition it reduces gastric emptying, thereby slowing the rate of nutrient absorption and reducing food intake. ${ }^{36}$ Liraglutide is an agonist on GLP-1 receptors used to diminish weight in obese diabetic and non-diabetic patients. Mean weight loss on daily subcutaneous dosages between $1.2-3 \mathrm{mg}$ during a 20 week period ranges from $4.8-7.2$ kg. ${ }^{37}$ Nausea and vomiting are the most common side-effects (45\%) and are experienced by $>5 \%$ of patients. Other adverse effects include hypoglycaemia, diarrhoea, constipation, headache, fatigue, dizziness, abdominal pain and increased lipase levels. Treatment should not exceed 12 months as there is an increased risk for developing pancreatitis. Liraglutide is contraindicated during pregnancy, gall bladder disease and thyroid abnormalities.

\section{Serotonin 2c agonists}

Pro-opiomelanocortin (POMC) is a protein present in the central nervous system. It is cleaved into several smaller peptides, each controlling important metabolic and physiological functions in the brain. One of these peptides, $\beta$-melanocyte stimulating hormone ( $\beta-\mathrm{MSH}$ ) interacts with the melanocortin 4 receptor in the hypothalamus which regulates the balance between energy from food taken into the body, and energy spent by the body. Eating and weight is thus maintained through this mechanism. ${ }^{38}$ Stimulation of $5-\mathrm{HT} 2 \mathrm{C}$ receptors in the hypothalamus enhances pro-opiomelanocortin production, resulting in weight loss through satiety. ${ }^{39}$ Lorcaserin, a selective serotonin 2 c receptor agonist, has been available in the United States since 2012 for 
the treatment of obesity with comorbid conditions. Its efficacy is comparable to orlistat, with an average weight loss of $3.6 \mathrm{~kg}$ in 12 weeks on a dose of $20 \mathrm{mg}$ per day. ${ }^{40}$ Side-effects are dosedependent, and include headache (18\%), nausea, dizziness, fatigue, dry mouth and constipation. ${ }^{41}$ It should not be taken by patients with renal dysfunction or those on other serotonergic agents due to the possibility of developing serotonin syndrome. Currently lorcaserin is not yet available in South Africa.

\section{Antiepileptic drugs}

Topiramate's mechanism of action as an antiepileptic involves the enhancement of GABA, and modifying the excitatory voltage-activated sodium and calcium channels in the brain. Its mechanism as an anti-obesity drug is not fully known, but studies indicate that it may increase the brain noradrenaline expression. Enhanced noradrenaline in the central nervous system resultantly suppresses appetite. ${ }^{42}$ Average weight loss on a dose between 96-200 mg per day for 28 weeks is approximately $6.5 \mathrm{~kg} .{ }^{43}$ The most common side-effects include paresthesia, psychomotor disturbances, memory impairment, diarrhoea and changes in vision. Topiramate is not recommended as a singleuse agent in the management of obesity.

\section{Atypical antidepressants}

Bupropion is a dopamine and noradrenaline reuptake inhibitor. Its mechanism is similar to other sympathomimetic agents, and is structurally related to diethylpropion. The additional effect of raising the dopamine concentration in the brain's reward centre (ventral tegmental area), makes it useful in treating depression, smoking cessation and suppression of appetite. Published literature reports an average weight loss of $4.4 \mathrm{~kg}$ in six months on a daily dose of $300 \mathrm{mg} .{ }^{44}$ Bupropion is ordinarily well-tolerated with few side-effects, but may cause agitation, headache, nausea, sweating and abdominal discomfort in rare instances.

\section{Hormones}

Various hormones acting on the hypothalamus play a role in appetite and energy homeostasis, some of which have been previously mentioned. One such hormone is leptin. It is secreted by the adipose tissue, gastric epithelium and placenta. Hypothalamic stimulation by leptin suppresses appetite and increases thermogenesis and metabolic rate in the long term. ${ }^{45}$ Obese individuals typically have high plasma leptin levels, but display insensitivity and resistance towards its hypothalamic stimulation. Early research done by Simeons recommended the injection of $125 \mathrm{iU}$ human chorionic gonadotropin (HCG) daily to restore hypothalamic-leptin sensitivity. The weight loss achieved by this method in combination with a calorie restricted diet was between 9-14 kg in six weeks. ${ }^{46}$ This observation has been refuted by many researchers, yet the act of injecting HCG is still widely practiced. Similarly the administration of thyroid hormones in euthyriotic obese patients is considered inappropriate, since the weight loss achieved is the result of a loss in lean muscle and not adipose tissue.

\section{Combination preparations}

As a result of the complex regulation of food intake and the multitude of mechanisms and pathways involved in energy homeostasis, it is suggested that combining two drugs with different mechanisms of action could improve efficacy, tolerability and the need for lower doses of individual drugs. Regulatory authorities seem to disagree on which combinations are suitable for registration and which ones are not. ${ }^{25}$ Currently there are no approved combination anti-obesity drugs registered by the South African Medicines Control Council, however the individual substances are available independently.

Phentermine (immediate release) and topiramate (extended release) capsules are only available in the USA. This combination should not be used in patients with cardiovascular disease such as hypertension, diabetes or dyslipidaemia, rendering it an inappropriate choice for the majority of obese patients. It carries a risk of increased congenital malformations, especially orofacial clefts when taken during the first trimester of pregnancy. It is considered as second-line therapy for obese postmenopausal women, or men without complicating risk factors not responding or unable to tolerate orlistat or lorcaserin. This formulation however appears to produce the largest mean weight loss (> 10\%) after two years treatment. ${ }^{47}$

Naltrexone and bupropion sustained release formulations have been available in Europe since 2012 and the USA from 2014. Both these drugs have anorectic properties and their combination proves favourable in the reduction of visceral fat. The proposed mechanism involves the increased firing rate of POMC neurons, leading to appetite suppression. ${ }^{48}$ The combination shows an increased risk of suicidal thoughts and behaviour and may precipitate seizures and adverse cardiovascular events in patients with epilepsy and uncontrolled hypertension. Expected weight loss is roughly $9 \mathrm{~kg}$ in a 24 week period.

\section{Conclusion}

Obesity rates are on the increase worldwide, and the cost to the healthcare system can be significant. Modest weight loss improves the risk of cardiovascular disease and morbidity. Although a multitude of measurements to classify obesity and its associated risks are well known, a precise clinical relevant golden standard is still lacking. All measurement tools should be seen as imperfect and patients must be assessed on individual merit. It remains the healthcare practitioner's imperative to adhere to acceptable management protocols. Various pharmacological substances are available and should be used in conjunction with advice on lifestyle modifications. Specific pharmacotherapy should be discontinued or re-evaluated if a weight loss of at least $5 \%$ is not achieved after six months. Bariatric surgery could be considered in individuals with a BMI of $\geq 35 \mathrm{~kg} / \mathrm{m}^{2}$. Patients should be made aware that drug therapy is not a cure for obesity and that further weight loss will cease when the maximal therapeutic effect of a drug is reached. Practitioners should be vigilant in identifying drugs with no scientific merit and council patients against their use.

\section{References}

1. World Health Organization. Obesity and overweight [Internet]. 2016 [updated January 2015; cited 2016 May 20]. Fact sheet No 311:[Available from: http:// www.who.int/topics/obesity/en/.

2. Finucane MM, Stevens GA, Cowan MJ; et al. National, regional, and global trends in body-mass index since 1980: systematic analysis of health examination 
surveys and epidemiological studies with 960 country-years and 9.1 million participants. Lancet. 2011;377(9765):557-67.

3. Kawahara R, Amemiya T. Obesity and diabetes mellitus. Asian Medical Journal. 1989;32(7):379-85.

4. Miner SES, Nield LE. Obesity Cardiovascular Disease and the Failure of Public Health Education. J Am Coll Cardiol. 2016;67(19):2315-6.

5. Shephard RJ. Exercise and cancer - linkages with obesity. Int J Obes. 1995;19:S62-S8.

6. Kortt M, Baldry J. The association between musculoskeletal disorders and obesity. Australian health review : a publication of the Australian Hospital Association. 2002;25(6):207-14.

7. Jeanrenaud B, Halimi S, van de Werve G. Neuro-endocrine disorders seen as triggers of the triad: obesity-insulin resistance-abnormal glucose tolerance. Diabetes/metabolism reviews. 1985;1(3):261-91.

8. Berman WH, Berman ER, Heymsfield $S$, et al. The incidence and comorbidity of psychiatric-disorders in obesity. J Pers Disord. 1992;6(2):168-75.

9. The Social Progress Imperative. Social Progress Index 2015 Report: Health and Wellness [Internet]. The Social Progress Imperative; 2016 [updated 14 April 2015; cited 2016 May 21]. Available from: http://www.socialprogressimperative.org/ data/spi\#data_table/countries/idr28/dim1,dim2,com7,idr28,dim3.

10. $\mathrm{Ng} \mathrm{M}$, Fleming $T$, Robinson $M$, et al. Global, regional, and national prevalence of overweight and obesity in children and adults during 1980-2013: a systematic analysis for the Global Burden of Disease Study 2013. Lancet.2013;384(9945):766-81.

11. Lang P. The works of Archimedes. J Hell Stud. 2005;125:193-4.

12. Kyle UG, Bosaeus I, De Lorenzo AD; et al. Bioelectrical impedance analysis-part II: utilization in clinical practice. Clin Nutr. 2004;23(6):1430-53.

13. Talma H, Chinapaw MJ, Bakker B, et al. Bioelectrical impedance analysis to estimate body composition in children and adolescents: a systematic review and evidence appraisal of validity, responsiveness, reliability and measurement error. Obes Rev. 2013;14(11):895-905.

14. Rothney MP, Brychta RJ, Schaefer EV, et al. Body Composition Measured by Dual-energy X-ray Absorptiometry Half-body Scans in Obese Adults. Obesity. 2009;17(6):1281-6

15. Frisancho AR. New norms of upper limb fat and muscle areas for assessment of nutritional status. Am J Clin Nutr. 1981;34(11):2540-5.

16. Watts K, Naylor LH, Davis EA; et al. Do skinfolds accurately assess changes in body fat in obese children and adolescents? Med Sci Sport Exer. 2006;38(3):439-44.

17. Rothman KJ. BMI-related errors in the measurement of obesity. Int J Obes. 2008;32(S3):S56-S9.

18. O'Neill D. Measuring obesity in the absence of a gold standard. Econ Hum Biol. 2015;17:116-28.

19. World Health Organization. Waist circumference and waist-hip ratio: Report of a WHO expert consultation [Internet]. Geneva 2011 [updated December 2008; cited 2016 May 23]. Available from: http://apps.who.int/iris/bitstr eam/10665/44583/1/9789241501491_eng.pdf?ua=1.

20. Wang YF, Rimm EB, Stampfer MJ, et al. Comparison of abdominal adiposity and overall obesity in predicting risk of type 2 diabetes among men. Am J Clin Nutr. 2005;81(3):555-63.

21. Bray GA, Ryan DH. Medical therapy for the patient with obesity. Circulation. 2012;125(13):1695-703.

22. Douketis JD, Macie $C$, Thabane $L$, et al. Systematic review of long-term weight loss studies in obese adults: clinical significance and applicability to clinical practice. Int J Obes. 2005;29(10):1153-67.

23. Leibel RL, Rosenbaum M, Hirsch J. Changes in energy-expenditure resulting from altered body-weight. N Engl J Med. 1995;332(10):621-8.

24. Stark $P$, Tooty CW. Effects of amphetamines on eating elicited by hypothalamic stimulation. J Pharmacol Exp Ther. 1967;158(2):272-8.
25. Krentz AJ, Fujioka K, Hompesch M. Evolution of pharmacological obesity treatments: focus on adverse side-effect profiles. Diabetes Obes Metab. 2016;18(6):558-70.

26. le Riche WH, Van Belle G. Study of Phendimetrazine Bitartrate as an Appetite Suppressant in Relation to Dosage, Weight Loss and Side Effects. Can Med Assoc J. 1962;87(1):29-31.

27. Kang JG, Park CY, Kang JH, et al. Randomized controlled trial to investigate the effects of a newly developed formulation of phentermine diffuse-controlled release for obesity. Diabetes Obes Metab. 2010;12(10):876-82.

28. Parsons WB, Jr. Controlled-release diethylpropion hydrochloride used in a program for weight reduction. Clin Ther. 1981;3(5):329-35.

29. Carlier H, Bernard A, Caselli C. Digestion and absorption of polyunsaturated fatty acids. Reprod Nutr Dev. 1991;31(5):475-500.

30. McNeely W, Benfield P. Orlistat. Drugs. 1998;56(2):241-9.

31. Van Gaal LF, Broom Jl, Enzi G, et al. Efficacy and tolerability of orlistat in the treatment of obesity: a 6-month dose-ranging study. Orlistat Dose-Ranging Study Group. Eur J Clin Pharmacol. 1998;54(2):125-32.

32. Jain SS, Ramanand SJ, Ramanand JB, et al. Evaluation of efficacy and safety of orlistat in obese patients. Indian J Endocrinol Metab. 2011;15(2):99-104.

33. Kokot F, Ficek R. Effects of neuropeptide $Y$ on appetite. Miner Electrolyte Metab. 1999;25(4-6):303-5.

34. Aubert G, Mansuy V, Voirol MJ, et al. The anorexigenic effects of metformin involve increases in hypothalamic leptin receptor expression. Metabolism. 2011;60(3):327-34.

35. Kay JP, Alemzadeh R, Langley $G$, et al. Beneficial effects of metformin in normoglycemic morbidly obese adolescents. Metabolism. 2001;50(12):1457-61.

36. Layer $\mathrm{P}$, Holst JJ, Grandt $D$, et al. Ileal release of glucagon-like peptide-1 (GLP-1). Association with inhibition of gastric acid secretion in humans. Dig Dis Sci. 1995;40(5):1074-82.

37. Astrup A, Rossner S, Van Gaal L; et al. Effects of liraglutide in the treatment of obesity: a randomised, double-blind, placebo-controlled study. Lancet. 2009;374(9701):1606-16.

38. Cone RD. Anatomy and regulation of the central melanocortin system. Nat Neurosci. 2005;8(5):571-8.

39. Feijo Fde M, Bertoluci MC, Reis C. Serotonin and hypothalamic control of hunger: a review. Rev Assoc Med Bras. 2011;57(1):74-7.

40. Smith SR, Prosser WA, Donahue DJ, et al. Lorcaserin (APD356), a selective $5-\mathrm{HT}(2 \mathrm{C})$ agonist, reduces body weight in obese men and women. Obesity. 2009;17(3):494-503.

41. DiNicolantonio JJ, Chatterjee S, O'Keefe JH, et al. Lorcaserin for the treatment of obesity? A closer look at its side effects. Open heart. 2014;1(1):e000173.

42. Handjieva-Darlenska T, Klisurov R. Effect of Topiramate on noradrenaline expression in the brain of dietary-induced obese rats (Preliminary data). Comptes Rendus De L Academie Bulgare Des Sciences. 2016;69(2):211-6.

43. Kramer CK, Leitao CB, Pinto LC, et al. Efficacy and safety of topiramate on weight loss: a meta-analysis of randomized controlled trials. Obes Rev. 2011;12(5):e338-47

44. Jain AK, Kaplan RA, Gadde KM; et al. Bupropion SR vs. placebo for weight loss in obese patients with depressive symptoms. Obes Res. 2002;10(10):1049-56.

45. Friedman JM, Halaas JL. Leptin and the regulation of body weight in mammals. Nature. 1998;395(6704):763-70.

46. Simeons AT. The action of chorionic gonadotrophin in the obese. Lancet. 1954;267(6845):946-7.

47. Alfaris N, Minnick AM, Hopkins CM, et al. Combination phentermine and topiramate extended release in the management of obesity. Expert Opin Pharmacother. 2015;16(8):1263-74.

48. Greenway FL, Whitehouse MJ, Guttadauria M; et al. Rational design of a combination medication for the treatment of obesity. Obesity. 2009;17(1):30-9. 